\title{
Activation of Muscarinic Acetylcholine Receptor Subtype 4 Is Essential for Cholinergic Stimulation of Gastric Acid Secretion: Relation to D Cell/Somatostatin
}

\author{
Koji Takeuchi1,2*, Takuya Endoh', Shusaku Hayashi' and Takeshi Aihara' \\ 'Division of Pathological Sciences, Department of Pharmacology and Experimental Therapeutics, Kyoto Pharmaceutical \\ University, Kyoto, Japan, ${ }^{2}$ General Incorporated Association, Kyoto Research Center for Gastrointestinal Diseases, Kyoto, \\ Japan
}

\section{OPEN ACCESS}

Edited by:

Ganna Tolstanova,

Taras Shevchenko National University

of Kyiv, Ukraine

Reviewed by:

Elisabetta Barocelli,

University of Parma, Italy

Muriel Larauche,

University of California, Los Angeles,

USA

*Correspondence:

Koji Takeuchi

takeuchi@mb.kyoto-phu.ac.jp

Specialty section:

This article was submitted to Gastrointestinal and Hepatic

Pharmacology,

a section of the journal

Frontiers in Pharmacology

Received: 15 June 2016 Accepted: 12 August 2016

Published: 30 August 2016

Citation:

Takeuchi K, Endoh T, Hayashi S and

Aihara T (2016) Activation of Muscarinic Acetylcholine Receptor Subtype 4 Is Essential for Cholinergic Stimulation of Gastric Acid Secretion: Relation to D Cell/Somatostatin.

Front. Pharmacol. 7:278 doi: 10.3389/fphar.2016.00278
Background/Aim: Muscarinic acetylcholine receptors exist in five subtypes $\left(M_{1} \sim M_{5}\right)$, and they are widely expressed in various tissues to mediate diverse autonomic functions, including gastric secretion. In the present study, we demonstrated, using M1 M5 KO mice, the importance of M4 receptors in carbachol (CCh) stimulation of acid secretion and investigated how the secretion is modulated by the activation of M4 receptors.

Methods: C57BL/6J mice of wild-type (WT) and M1-M5 KO were used. Under urethane anesthesia, acid secretion was measured in the stomach equipped with an acute fistula. CCh $(30 \mu \mathrm{g} / \mathrm{kg}$ ) was given subcutaneously (s.c.) to stimulate acid secretion. Atropine or octreotide (a somatostatin analog) was given s.c. 20 min before the administration of CCh. CYN154806 (a somatostatin SST2 receptor antagonist) was given i.p. 20 min before the administration of octreotide or CCh.

Results: CCh caused an increase of acid secretion in WT mice, and the effect was totally inhibited by prior administration of atropine. The effect of CCh was similarly observed in the animals lacking M1, M2 or M5 receptors but significantly decreased in M3 or M4 KO mice. CYN154806, the SST2 receptor antagonist, dose-dependently and significantly reversed the decreased acid response to CCh in M4 but not M3 $\mathrm{KO}$ mice. Octreotide, the somatostatin analog, inhibited the secretion of acid under CCh-stimulated conditions in WT mice. The immunohistochemical study showed the localization of $\mathrm{M}_{4}$ receptors on $\mathrm{D}$ cells in the stomach. Serum somatostatin levels in $\mathrm{M} 4$ $\mathrm{KO}$ mice were higher than WT mice under basal conditions, while those in WT mice were significantly decreased in response to CCh.

Conclusions: These results suggest that under cholinergic stimulation the acid secretion is directly mediated by M3 receptors and indirectly modified by M4 receptors. It is assumed that the activation of M4 receptors inhibits the release of somatostatin from D cells and minimizes the acid inhibitory effect of somatostatin through SST2 receptors, resulting in enhancement of the acid response mediated by M3 receptors on parietal cells.

Keywords: acid secretion, isolated mouse stomach, carbachol, somatostatin, knockout mouse, muscarinic receptor subtypes, SST2 receptor 


\section{INTRODUCTION}

The mechanisms that govern gastric acid secretion involve neurohumoral factors, including histamine, gastrin, and acetylcholine (ACh; Soll, 1994; Hersey and Sachs, 1995; Chen et al., 2004). The action of histamine is mediated intracellularly by $3^{\prime}, 5^{\prime}$ cyclic adenosine monophosphate (cAMP), while those of gastrin and $\mathrm{ACh}$ are mediated by an increase of intracellular $\mathrm{Ca}^{2+}$ (Thurston et al., 1979). The stimulatory actions of histamine and gastrin are mediated by the activation of histamine $\mathrm{H}_{2}$ and cholecystokinin (CCK)-2 receptors, respectively (Brimblecombe et al., 1978; Hersey and Sachs, 1995; Chen et al., 2004), and that of ACh is caused by the activation of muscarinic acetylcholine receptors (mAChRs; Soll, 1994; Caulfield and Birdsall, 1998).

The mAChRs consist of five subtypes (M1-M5) and are widely expressed in many peripheral organs as well as central nervous system to mediate diverse autonomic functions, including acid, pepsin and mucus as well as $\mathrm{HCO}_{3}^{-}$secretions (Kajimura et al., 1992; Helander et al., 1996; Caulfield and Birdsall, 1998; Matsui et al., 2000, 2004; Tobin et al., 2009). These receptors are G protein-coupled receptors; M1, M3, and M5 receptors are coupled to Gq protein, while M2 and M4 receptors are coupled to Gi protein (Caulfield and Birdsall, 1998; Matsui et al., 2000). It is generally accepted that the acid stimulatory action of carbachol (CCh), a muscarinic agonist, is mediated by the activation of M1 and M3 receptors (Nakamura et al., 1985; Pfeiffer et al., 1990). However, Aihara et al. (2005) examined the involvement of M1, $\mathrm{M} 3$, and $\mathrm{M} 5$ receptors in cholinergic regulation of acid secretion using muscarinic receptor knockout (KO) mice and found that CCh-stimulated acid secretion is mediated by mainly M3 and partially $\mathrm{M} 5$ but not M1 receptors. In addition, we recently found that CCh-induced duodenal $\mathrm{HCO}_{3}^{-}$secretion was markedly decreased in $\mathrm{M} 4 \mathrm{KO}$ mice, suggesting the involvement of M4 receptors in the cholinergic stimulation of $\mathrm{HCO}_{3}^{-}$secretion (Takeuchi et al., 2015). However, no information is currently available on the role of M4 receptors in the cholinergic regulation of gastric acid secretion.

Somatostatin, a peptide hormone, regulates many physiological functions in the gastrointestinal tract (Lucey and Yamada, 1989). This peptide is produced and secreted from D cells and inhibits acid secretion through a tonic inhibitory effect on both parietal and enterochromaffin-like cells via the activation of $\mathrm{G}$ protein-coupled SST2 receptors (Warhurst et al., 1996; Patel, 1997; Piqueras and Martínez, 2004). Chiba and Yamada (1990) reported that CCh inhibited both basal and pentagastrin-stimulated somatostatin secretion in the isolated canine D cells in a Gi protein/cAMP-dependent manner. We reported the involvement of somatostatin in the regulatory mechanism of the CCh-stimulated $\mathrm{HCO}_{3}^{-}$secretion (Takeuchi et al., 2015). It is thus possible that endogenous somatostatin may also be involved in the mechanism of gastric acid secretion in response to cholinergic stimulation, although no study has tested this hypothesis.

In the present study, we examined the effects of $\mathrm{CCh}$ on gastric acid secretion in wild-type (WT) and mAChR KO mice lacking M1-M5 receptors, and investigated the involvement of
M4 receptors in the stimulatory action of CCh. We demonstrated the importance of M4 receptors in the cholinergic stimulation of gastric acid secretion and showed how this secretion can be modulated by the activation of M4 receptors, particularly focusing on the relation to D cell/somatostatin.

\section{MATERIALS AND METHODS}

\section{Animals}

Age-matched male C57BL/6J mice, weighing 25 30 g of WT and those lacking M1, M2, M3, M4, or M5 receptor, were used. The generation and characterization of each subtype of mAChR KO mouse strain has been previously described by others (Matsui et al., 2000; Ohno-Shosaku et al., 2003; Nakamura et al., 2004). Animals were housed in plastic cages with hardwood chips in an air-conditioned room $\left(25^{\circ} \mathrm{C}\right)$, and were given standard dry pellets, CA-1 (CLEA Japan, Tokyo, Japan) and water ad libitum. All experimental procedures used were carried out in accordance with the Helsinki Declaration and have been approved by the Committee for Animal Experimentation established by Kyoto Pharmaceutical University.

\section{Determination of Gastric Acid Secretion}

Acid secretion was measured in acute fistula stomachs of both WT and M1-M5 KO mice according to a previously published method (Niida et al., 1991; Kitamura et al., 1999). Under urethane anesthesia $[1.25 \mathrm{~g} / \mathrm{kg}$, intraperitoneally (i.p.)], the trachea was cannulated to ensure a patent airway, and the body temperature was maintained at $36 \pm 1{ }^{\circ} \mathrm{C}$ using a heating lamp. Then, the abdomen was incised, both the stomach and duodenum were exposed, and the cardiac portion was ligated without interfering with vagus nerves. An acute fistula (inside diameter, $2 \mathrm{~mm}$ ) made with a polyethylene tube was inserted into the stomach from a small incision made in the duodenum and held in place by a ligature around the pylorus. At the beginning of each experiment, the stomach was rinsed several times with physiological saline $(154 \mathrm{mM} \mathrm{NaCl})$ and filled with $0.4 \mathrm{ml}$ of saline for $20 \mathrm{~min}$ for determination of the basal secretion. Then, the stomach was instilled with $0.4 \mathrm{ml}$ of saline, and the solution was changed every $20 \mathrm{~min}$. The collected samples were titrated to $\mathrm{pH} 7.0$ against $2 \mathrm{mM} \mathrm{NaOH}$ using an autoburette (Comitite-8; Hiranuma, Tokyo, Japan). Gastric acid secretion was stimulated by CCh given subcutaneously (s.c.) in a dose of $30 \mu \mathrm{g} / \mathrm{kg}$ in both WT and KO mice lacking M1M5 receptors. In WT mice, atropine $(0.1$ and $0.3 \mathrm{mg} / \mathrm{kg})$ or octreotide (a somatostatin analog: $20 \mu \mathrm{g} / \mathrm{kg}$ ) was given s.c. $20 \mathrm{~min}$ before the administration of CCh. In some cases CYN154806 (a somatostatin SST2 receptor antagonist: $0.1 \mathrm{mg} / \mathrm{kg}$; Feniuk et al., 2000) was given i.p. 20 min before the administration of octreotide $(20 \mu \mathrm{g} / \mathrm{kg})$ in WT mice or the administration of $\mathrm{CCh}(30 \mu \mathrm{g} / \mathrm{kg})$ in M4 KO mice. Control animals received saline or vehicle in place of the active agent. The doses of atropine, octreotide or CYN154806 were selected in order to induce the respective pharmacological actions according to the findings of previously published studies (Aihara et al., 2005; Xie et al., 2005; Terashima et al., 2009). 


\section{Analyses for Gene Expression of mRNAs of mAChR Subtypes in Mouse Stomachs}

Whole stomachs were collected from both WT mice and those lacking M1-M5 receptors, and immediately frozen in liquid nitrogen and stored at $-80^{\circ} \mathrm{C}$ until use. Total RNA was extracted from tissue samples using Sepasol RNA I (Nacalai Tesque, Kyoto, Japan). Total RNA was reverse-transcribed with a first strand cDNA synthesis kit (ReverTra Ace alpha, TOYOBO, Osaka, Japan; Amagase et al., 2010). The sequences of the sense and antisense primers for mouse M1-M5 receptors and GAPDH, and the sizes of the expected RT-PCR products are shown in Table 1. An aliquot of the RT reaction product served as a template in 35 cycles of PCR with $0.5 \mathrm{~min}$ of denaturation at $95^{\circ} \mathrm{C}$ and 1 min of extension at $68^{\circ} \mathrm{C}$ using the Advantage 2 polymerase mixture (CLONTECH, Mountain View, CA, USA) in a thermal cycler (PC-806, ASTEC, Fukuoka, Japan; Hayashi et al., 2014). A portion of the PCR mixture was electrophoresed in 1.5\% agarose gel in Tris-acetic acid-EDTA buffer ( $40 \mathrm{mM}$ Tris, $20 \mathrm{mM}$ acetic acid, and 2 mM EDTA; $\mathrm{pH} 8.1$ ), and the gel was stained with ethidium bromide and photographed (Bio Doc-It Imaging System; UVP, Upland, CA, USA). Images were analyzed with the Image $J$ (version 1.39), and the semi-quantitative measurement of mRNA expression was presented as a ratio compared with GAPDH (Nakamori et al., 2010; Hayashi et al., 2014).

\section{Immunohistological Study}

Expressions of mAChR M4 receptor and somatostatin were immunohistochemically examined in the gastric mucosa of WT or M4 KT mice. The stomachs were excised, rinsed with icecold PBS, and embedded in O.C.T. compound (Tissue-Tek, Sakura, Tokyo, Japan) iced with liquid $\mathrm{CO}_{2}$. Frozen samples were sectioned at a thickness of $10 \mu \mathrm{m}$ at $-20^{\circ} \mathrm{C}$ using a cryostat microtome (Leica Biosystems CM1510, Nussloch, Germany). The sections were exposed to $3 \%$ bovine serum albumin solution for $1 \mathrm{~h}$ to reduce the non-specific binding of anti-sera. The sections were exposed to each primary antibody for $16 \mathrm{~h}$ at $4^{\circ} \mathrm{C}$, and incubated with the appropriate secondary antibody for $2 \mathrm{~h}$ at a room temperature. The sections were mounted with

TABLE 1 | Sequences of sense and antisense primers for mouse M1-M5 receptors.

\begin{tabular}{lll}
\hline & Sequences & $\begin{array}{l}\text { PCR } \\
\text { products }\end{array}$ \\
\hline Ml sense & 5'-GCAGCAGCTCAGAGAGGTCACAG-3' & $413 \mathrm{bp}$ \\
antisense & 5'-GATGAAGGCCAGCAGGATGG-3 & \\
M2 sense & 5'-GCGGATCCTGTGGCCAACCAAGAC-3' & $441 \mathrm{bp}$ \\
antisense & 5'-CGATTCACGATTGCGGGCTA-3' & \\
M3 sense & 5'-AAGGCACCAAACGCTCATCT-3' & $511 \mathrm{bp}$ \\
antisense & 5'-GCAAACCTCTTAGCCAGCGT-3' & \\
M4 sense & 5'-AGCCGCAGCCGTGTCACAA-3' & $345 \mathrm{bp}$ \\
Antisense & 5'-TGGGTTGAGGGTCGTGGCT-3' & \\
M5 sense & 5'-GTCTCCGTCATGACCATACTCTA-3' & $230 \mathrm{bp}$ \\
Antisense & 5'-CCCGTTGTTGAGGTGCTTCTAC-3' & \\
GAPDH sense & 5'-GAACGGGAAGCTCACTGGCATGGC-3' & $191 \mathrm{bp}$ \\
antisense & 5'-TGAGGTCCACCACCCTGTTGCTG-3' &
\end{tabular}

VECTASHIELD mounting medium, including 4,6-diamidino2- phenylindole (Vector Laboratories, Peterborough, UK). The preparations were observed using a fluorescence microscope (Olympus BX51, Tokyo, Japan) and photographed using an Olympus digital camera. The following primary antibodies were used: rabbit anti-mAChR M4 and goat anti-Somatostatin (Santa Cruz Biotechnology, Santa Cruz, CA, USA). Alexa Fluor 488 conjugated donkey anti-rabbit IgG and Alexa Fluor 546 conjugated donkey anti-goat IgG (Molecular Probes, Eugene, OR, USA) were used as secondary antibodies.

\section{Determination of Serum Somatostatin Levels}

Serum levels of somatostatin were measured in both WT and $\mathrm{M} 4 \mathrm{KO}$ mice before and after the s.c. administration of $\mathrm{CCh}$ $(30 \mu \mathrm{g} / \mathrm{kg}$ ), according to a previously published paper (Terashima et al., 2009). Thirty minutes after each treatment, blood was collected from the descending aorta. Then, blood samples were centrifuged at $6000 \mathrm{~g}$ for $15 \mathrm{~min}$, and the supernatant of each sample was frozen at $20^{\circ} \mathrm{C}$ until the measurement of somatostatin. The concentration of somatostatin was measured with a somatostatin immunoassay kit (Peninsula Laboratories, Inc., San Carlos, CA, USA).

\section{Preparation of Drugs}

Drugs used were urethane (Tokyo Kasei, Tokyo, Japan), carbamylcholine chloride [carbachol: CCh], octreotide, CYN154806 (Sigma-Aldrich, St. Louis, MO, USA), and atropine sulfate (Nacalai tesque, Kyoto, Japan). CCh and atropine were dissolved in saline, while octreotide and CYN154806 were dissolved in dimethyl sulfoxide (DMSO: Wako, Osaka, Japan) and diluted with distilled water to desired concentrations. Each agent was prepared immediately before use and administered as a single injection s.c. or i.p. in a volume of $1 \mathrm{ml}$ per $100 \mathrm{~g}$ body weight.

\section{Statistical Analysis}

Data are presented as means \pm SE. Differences between two groups were evaluated with the Student's $t$-test. Differences between multiple groups were evaluated with analysis of variance followed, when necessary, by a Dunnett's multiple comparison test. Values of $P<0.05$ were considered statistically significant.

\section{RESULTS}

\section{Effect of CCh on Gastric Acid Secretion in WT Mice}

Under urethane anesthesia the stomachs of WT mice spontaneously secreted acid secretion in almost negligible amount of less than $0.1-0.2 \mu \mathrm{mol} / 20 \mathrm{~min}$. Subcutaneously administered CCh $\quad(30 \quad \mu \mathrm{g} / \mathrm{kg})$ significantly stimulated acid secretion; the acid secretion reached a peak value of $3.8 \pm 0.5 \mu \mathrm{mol} / 20 \mathrm{~min} 20 \mathrm{~min}$ after the administration, followed by a gradual decrease to near basal levels $100 \mathrm{~min}$ later (Figure 1A). Pretreatment of the animals with atropine $(0.1$ 

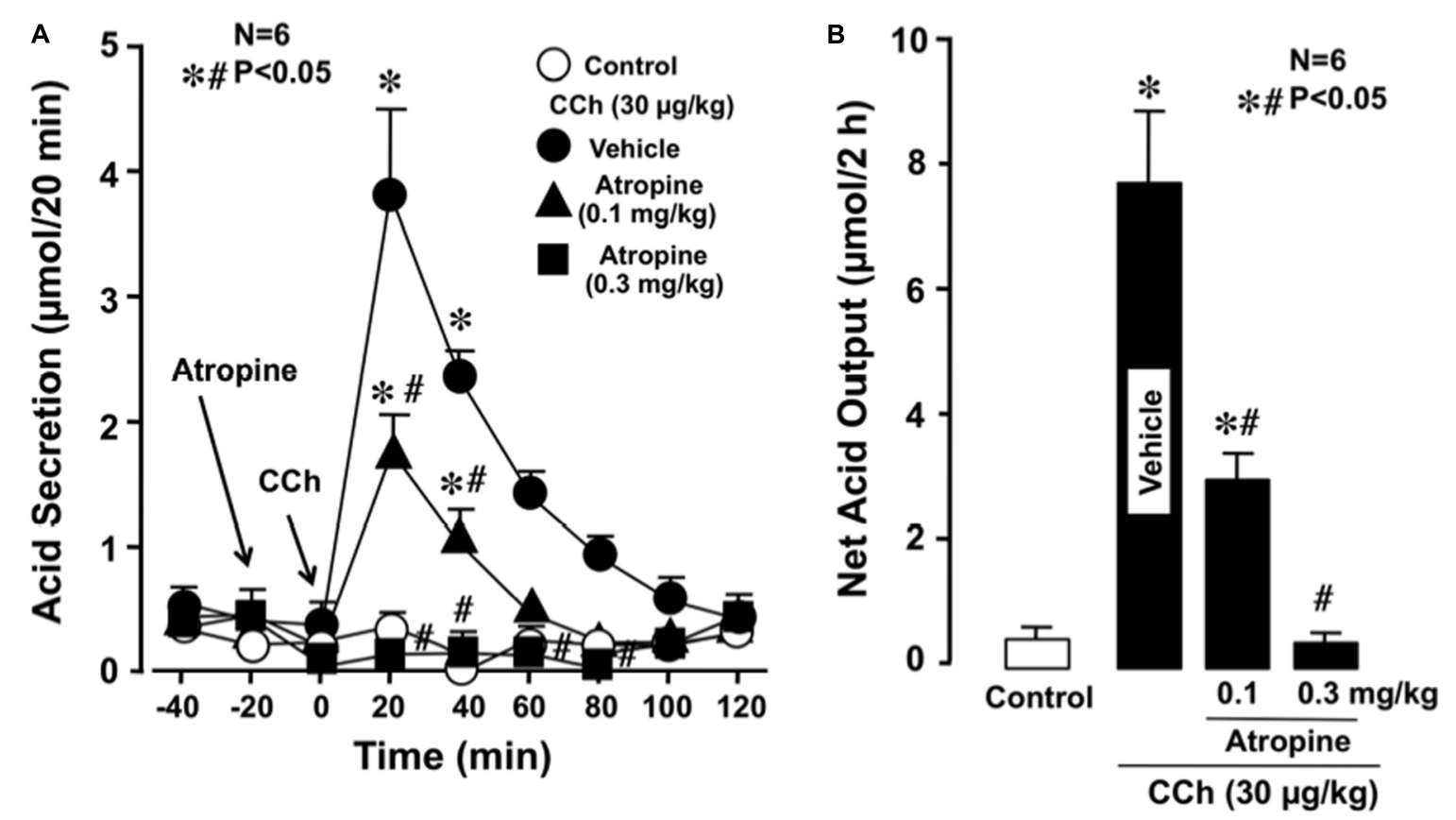

FIGURE 1 | Effects of atropine on CCh-stimulated acid secretion in the stomach of WT mice. CCh ( 30 $\mu \mathrm{g} / \mathrm{kg})$ was administered s.C. as a single injection. Atropine (0.1 and $0.3 \mathrm{mg} / \mathrm{kg}$ ) was given s.c. 20 min before the administration of CCh. (A) Data are presented as the mean \pm SE of values determined every 20 min from six mice. (B) Shows the total net acid output for $2 \mathrm{~h}$ after the administration of CCh, and the data are presented as the mean \pm SE from six mice. Significant difference at $P<0.05$; * from control; \# from Vehicle.

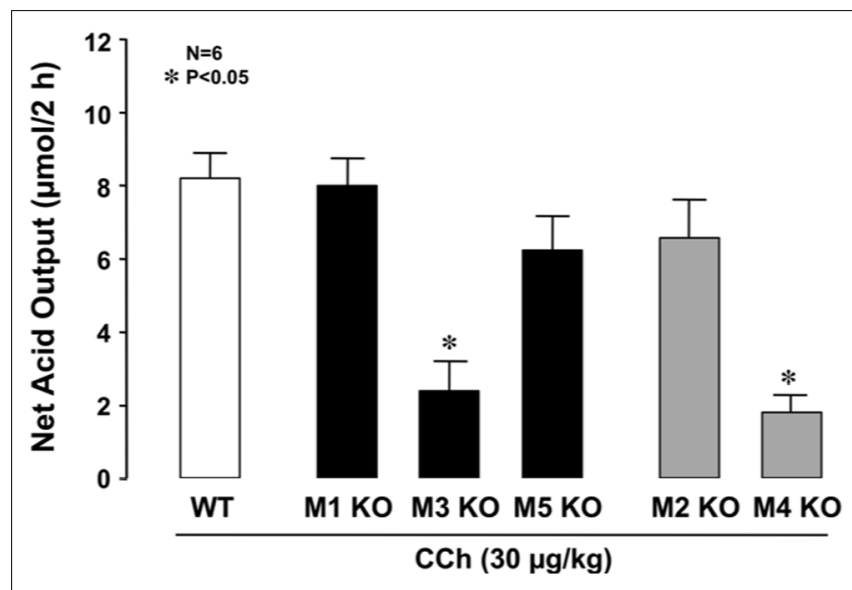

FIGURE 2 | Effects of CCh on acid secretion in the stomachs of WT mice and those of $\mathrm{KO}$ animals lacking M1-M5 receptors. CCh

(30 $\mu \mathrm{g} / \mathrm{kg})$ was administered s.c. as a single injection. Data show the total net acid output for $2 \mathrm{~h}$ after the administration of $\mathrm{CCh}$ and are presented as the mean \pm SE from six mice. * Significant difference from WT at $p<0.05$. and $0.3 \mathrm{mg} / \mathrm{kg}$, s.c.) dose-dependently inhibited the increase of acid secretion in response to $\mathrm{CCh}$, and the net acid output at 0.1 and $0.3 \mathrm{mg} / \mathrm{kg}$ was $2.8 \pm 0.3$ and $0.3 \pm 0.1 \mu \mathrm{mol} / 2 \mathrm{~h}$, respectively, both of which were significantly lower than that $(7.9 \pm 1.3 \mu \mathrm{mol} / 2 \mathrm{~h})$ of control mice given CCh plus vehicle (Figures 1A,B).

\section{Effect of CCh on Gastric Acid Secretion in $\mathrm{mAChR}$ KO Mice}

Since the acid stimulatory action of $\mathrm{CCh}$ was almost completely inhibited by atropine, the non-selective antagonist of mAChR, these results confirmed that $\mathrm{CCh}$ stimulated gastric acid secretion via the activation of mAChRs. We then investigated the subtype(s) of mAChRs involved in the regulation of gastric acid secretion, we examined the effects of CCh on acid secretion in the stomachs of mAChR KO mice lacking M1, M2, M3, M4, or M5 receptors.

The stomachs of both WT and various mAChR KO mice consistently secreted $0.1 \sim 0.3 \mu \mathrm{mol} / 20 \mathrm{~min}$ of $\mathrm{H}^{+}$as basal secretion, and no significant difference was observed in the basal rates of the stomachs of these animals (data not shown). The stimulatory action of CCh (30 $\mu \mathrm{g} / \mathrm{kg}$, s.c.) was similar between $\mathrm{mAChR} \mathrm{KO}$ mice lacking $\mathrm{M} 1$ and $\mathrm{M} 2$ receptors and WT mice, with the net acid outputs being $8.0 \pm 0.8 \mu \mathrm{mol} / 2 \mathrm{~h}$ and $6.8 \pm 0.9 \mu \mathrm{mol} / 2 \mathrm{~h}$, respectively, which were almost equivalent to that $(8.1 \pm 0.7 \mu \mathrm{mol} / 2 \mathrm{~h})$ in WT mice (Figure 2). Although a slight decrease in the acid response to CCh was observed in M5 KO mice, the net acid output $(6.4 \pm 0.7 \mu \mathrm{mol} / 2 \mathrm{~h})$ was not statistically significant from that of WT mice. In contrast, the acid response to CCh was significantly decreased in M3 and M4 $\mathrm{KO}$ mice, with the net acid outputs being $2.3 \pm 0.9 \mu \mathrm{mol} / 2 \mathrm{~h}$ and $2.1 \pm 0.5 \mu \mathrm{mol} / 2 \mathrm{~h}$, respectively. As shown in Figure 3A, CCh-stimulated acid secretion was markedly decreased in M4 KO mice. In WT mice the secretion of acid reached a peak value of $4.7 \pm 0.7 \mu \mathrm{mol} / 20 \mathrm{~min}$ with the net acid output being 
A

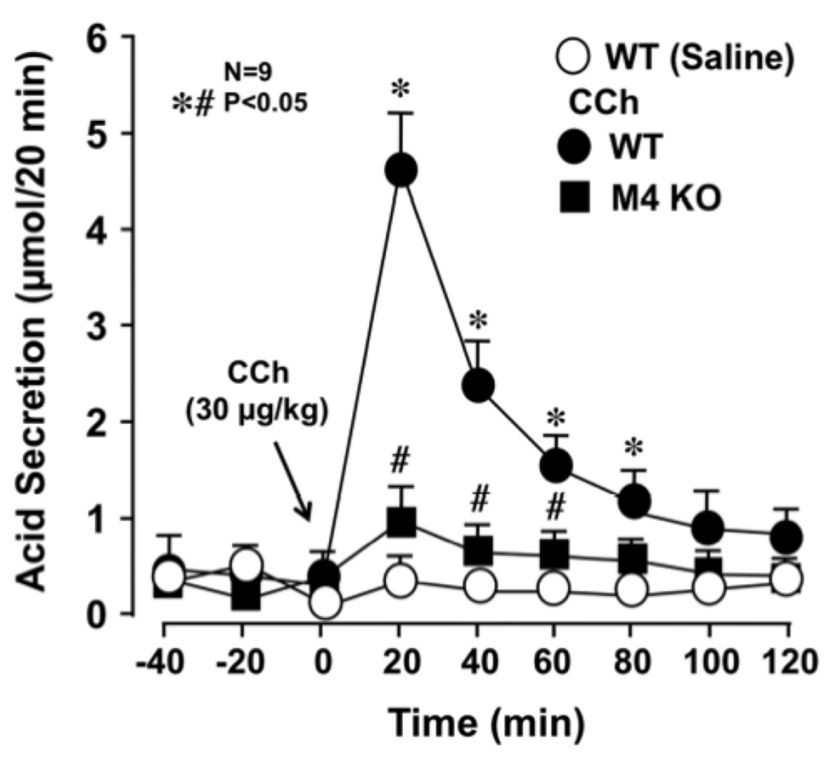

B

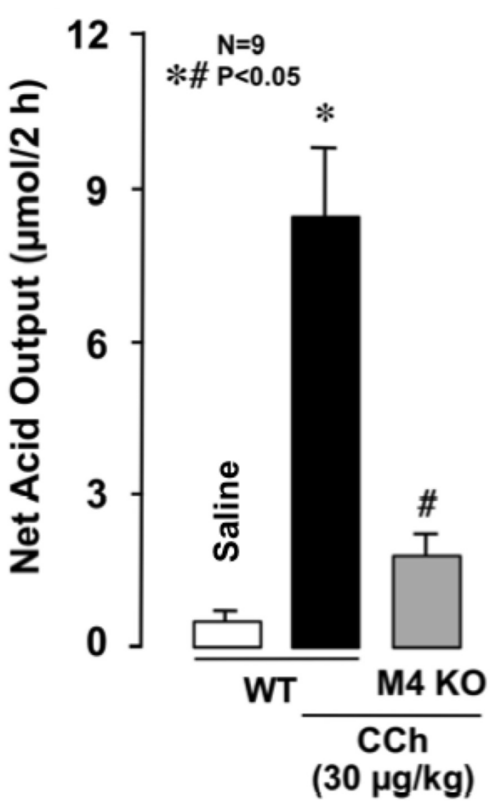

FIGURE 3 | Effects of CCh on acid secretion in the stomachs of WT and M4 KO mice. CCh (30 $\mu \mathrm{g} / \mathrm{kg})$ was administered s.C. as a single injection. (A) The data are presented as the mean \pm SE of values determined every 20 min from nine mice. (B) Shows the total net acid output for $2 \mathrm{~h}$ after the administration of CCh, and the data are presented as the mean \pm SE from nine mice. Significant difference at $p<0.05 ;{ }^{*}$ from Saline in WT; \# from CCh in WT.

$8.5 \pm 1.2 \mu \mathrm{mol} / 2 \mathrm{~h}$, while in $\mathrm{M} 4 \mathrm{KO}$ mice the peak value was $1.0 \pm 0.2 \mu \mathrm{mol} / 20 \mathrm{~min}$ with the net acid output being $1.8 \pm 0.3 \mu \mathrm{mol} / 2 \mathrm{~h}$, which was significantly lower than that in WT mice (Figure 3B).

\section{Effects of Somatostatin on Gastric Acid Secretion in WT Mice}

Somatostatin has been shown to inhibit secretory and motor functions in the gastrointestinal tract and antagonizes the actions of several hormones (Lucey and Yamada, 1989; Piqueras and Martínez, 2004; Takeuchi et al., 2015). Since the release of somatostatin from $\mathrm{D}$ cells is known to be mediated by an increase in cAMP (Lucey and Yamada, 1989), and the activation of M4 receptors is coupled with $\mathrm{Gi}$ protein to inhibit adenylate cyclase (Caulfield and Birdsall, 1998; Tobin et al., 2009), it is possible that the decreased acid response observed in M4 KO mice may be associated with changes in somatostatin secretion. Therefore, we examined the effects of octreotide, an analog of somatostatin, on gastric acid secretion in WT mice under CCh-stimulated conditions.

The basal secretion of acid in WT mice was very scanty with less than $0.1 \sim 2 \mu \mathrm{mol} / 20 \mathrm{~min}$ and did not show significant changes following the s.c. administration of octreotide $(20 \mu \mathrm{g} / \mathrm{kg})$. However, the gastric acid response induced by $\mathrm{CCh}$ $(30 \mu \mathrm{g} / \mathrm{kg}$ ) was markedly reduced by the prior administration of octreotide; the net acid output was $0.7 \pm 0.6 \mu \mathrm{mol} / 2 \mathrm{~h}$, which was highly significantly different from that $(8.5 \pm 1.9 \mu \mathrm{mol} / 2 \mathrm{~h})$ of WT mice (Figures 4A,B). This inhibitory effect of octreotide was completely abrogated when CYN154806 (0.1 mg/kg), a SST2 antagonist, was given $20 \mathrm{~min}$ before the administration of octreotide; the net acid output in response to CCh was $9.5 \pm 0.8 \mu \mathrm{mol} / 2 \mathrm{~h}$, which was almost equivalent to that of WT mice.

\section{Effects of the Somatostatin SST2 Receptor Antagonist CYN154806 on Gastric Acid Response to CCh in M4 KO Mice}

We demonstrated that octreotide, an exogenous somatostatin analog, significantly inhibited CCh-stimulated secretion of acid in the stomachs of WT mice. Since it has been shown that CCh inhibited both basal and pentagastrin-stimulated somatostatin secretion in rats (Chiba and Yamada, 1990), there may be some interaction between somatostatin secretion and CChstimulated acid secretion. Then, to investigate the involvement of endogenous somatostatin in the decreased acid response to $\mathrm{CCh}$ in M4 KO mice, we examined the effects of CYN154806, a SST2 receptor antagonist, on the CCh-stimulated acid secretion in M4 KO mice.

Subcutaneously administered CCh $(30 \mu \mathrm{g} / \mathrm{kg})$ markedly increased acid secretion in the stomachs of WT mice, the peak value of acid secretion was $4.2 \pm 0.2 \mu \mathrm{mol} / 20 \mathrm{~min}$ and the net acid output was $8.2 \pm 1.3 \mu \mathrm{mol} / 2 \mathrm{~h}$ (Figures 5A,B). By contrast, CCh did not increase acid secretion in the stomachs of M4 KO mice; the peak value of acid secretion was $0.9 \pm 0.1 \mu \mathrm{mol} / 20 \mathrm{~min}$, while the net acid output was 
A

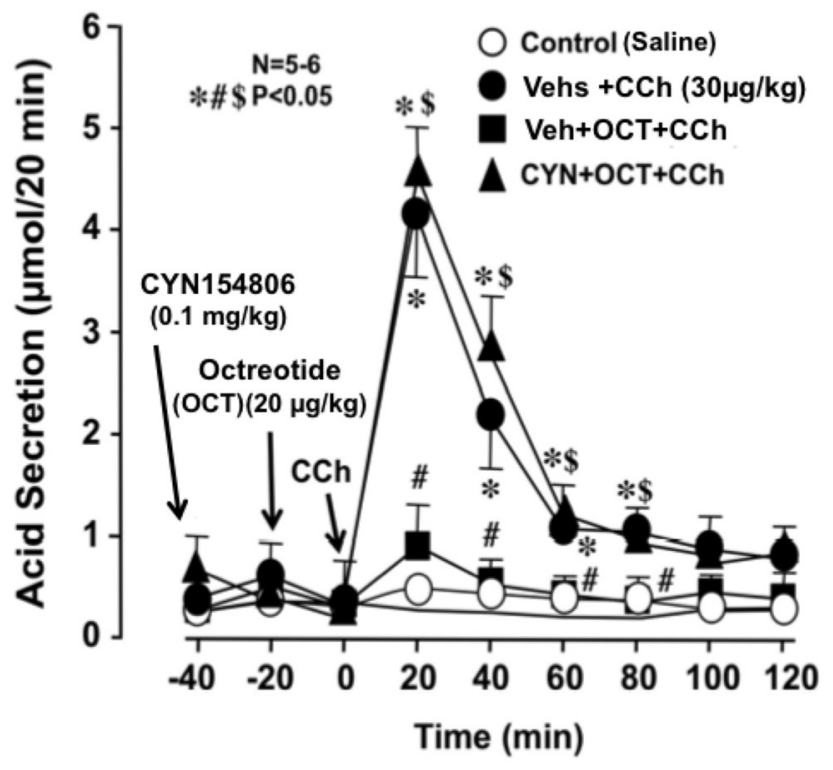

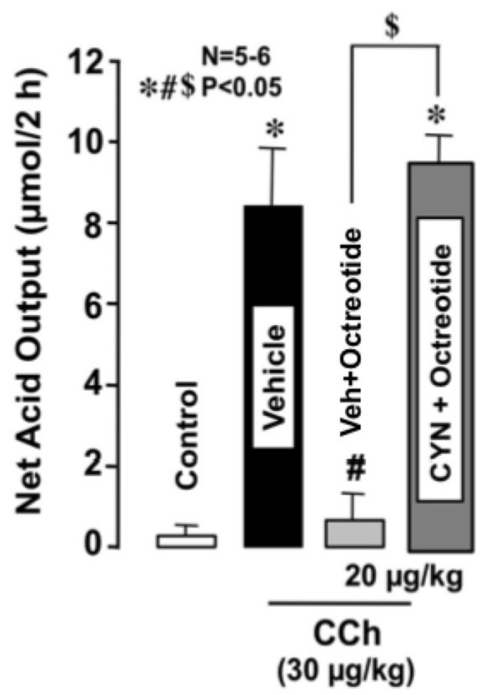

FIGURE 4 | Effects of octreotide on CCh-stimulated acid secretion in the stomachs of WT mice. CCh $(30 \mu \mathrm{g} / \mathrm{kg})$ was administered s.c. as a single injection. Octreotide $(20 \mu \mathrm{g} / \mathrm{kg})$, an analog of somatostatin-14, was administered s.c. 20 min before the administration of CCh, while CYN154806 (0.1 mg/kg), a SST2 antagonist, was given i.p. 20 min before the administration of octreotide. (A) The data are presented as the mean \pm SE of values determined every 20 min from 5 to 6 mice. (B) Shows the total net acid output for $2 \mathrm{~h}$ after the administration of CCh, and the data are presented as the mean \pm SE from 5 to 6 mice. Significant difference at $P<0.05 ; *$ from Control (saline); \# from Vehicle + CCh; $\$$ from Vehicle + Octreotide + CCh.

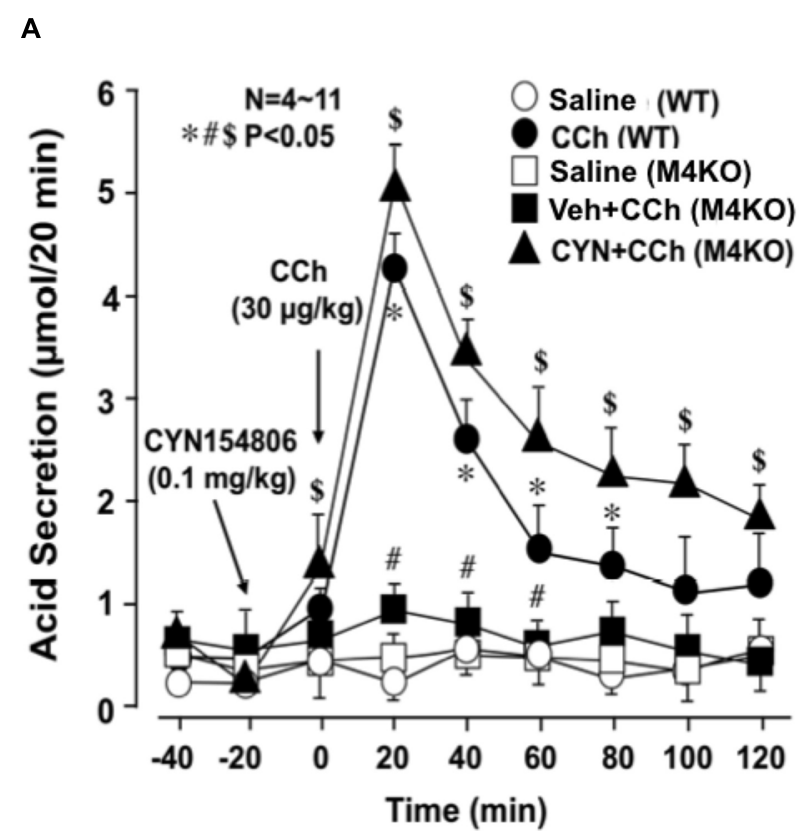

B

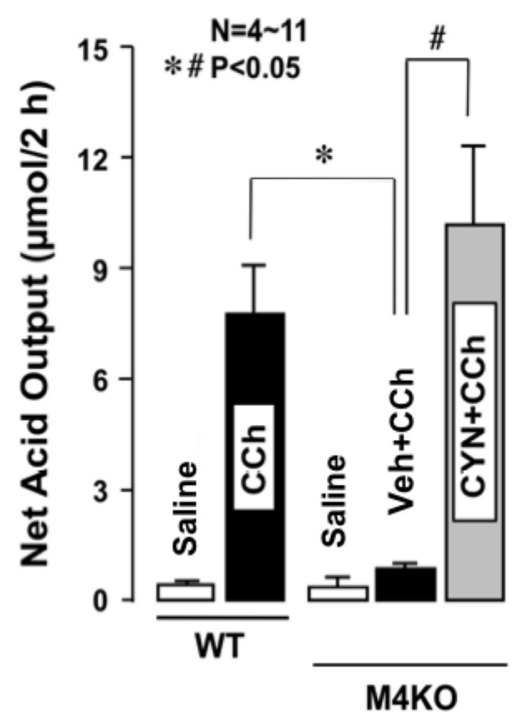

FIGURE 5 | Effects of CCh on acid secretion in the stomachs of WT and M4 KO mice, with or without the pretreatment of CYN154806. CCh (30 $\mu \mathrm{g} / \mathrm{kg})$ was administered s.c. as a single injection. CYN154806 (0.1 mg/kg) was administered i.p. 20 min before the administration of CCh. (A) The data are presented as the mean \pm SE of values determined every 20 min from 4 to 11 mice. Significant difference at $p<0.05, *$ from Saline (WT), \# from CCh (WT), \$ from Vehicle + CCh (M4KO). (B) Shows the total net acid output for $2 \mathrm{~h}$ after the administration of CCh, and the data are presented as the mean \pm SE of values determined every 10 min

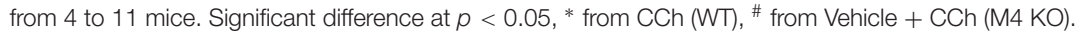




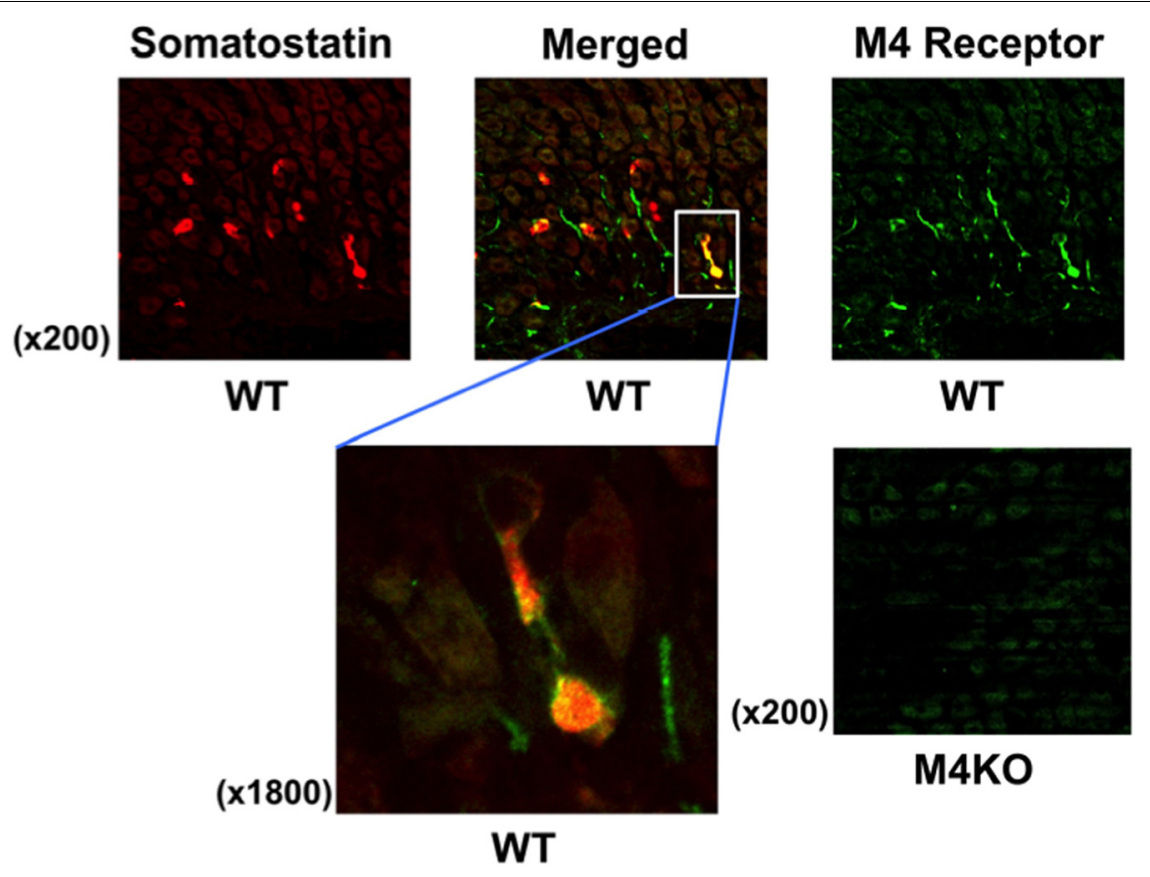

FIGURE 6 | Fluorescence immunochemical staining of the gastric mucosa with anti-somatostatin and anti-M4 receptor antibodies in WT or M4 KO mice. Somatostatin was stained red, while M4 receptor was stained green. The left of the lower panels shows higher magnification to indicate the co-expression of $\mathrm{M} 4$ receptors with somatostatin on D cells in a WT mouse stomach as visualized as yellow in the merged image. In the right of the lower panels showed that M4 receptors were not observed in the gastric mucosa of a M4 KO mouse.

$1.0 \pm 0.8 \mu \mathrm{mol} / 2 \mathrm{~h}$, which was almost equivalent to that in the stomachs of M4 KO treated with saline. However, when M4 KO mice were pretreated i.p. with CYN154806 (0.1 mg/kg), the administration of CCh potently increased acid secretion; the peak value was $5.1 \pm 0.3 \mu \mathrm{mol} / 20 \mathrm{~min}$, while the net acid output was $10.1 \pm 2.5 \mu \mathrm{mol} / 2 \mathrm{~h}$, which was significantly greater than that of M4 KO mice without pretreatment of CYN154806. The decreased acid response to CCh in $\mathrm{M} 3 \mathrm{KO}$ mice was not affected by CYN154806 (data not shown).

\section{Immunostaining of Somatostatin and M4 Receptors in Stomach of WT and M4 KO Mice}

To examine the presence of M4 receptors in D cells, we performed the immunostaining of the gastric mucosa with anti-somatostatin and anti-M4 receptor antibodies in WT mice. As expected, the expression of somatostatin was clearly observed in the stomach of WT mouse; it was stained red (Figure 6). On the other hand, the immunostaining of M4 receptors was also observed in the same area of the stomach; the higher magnification showed the co-existence of M4 receptors with somatostatin (a left figure of the lower panel), suggesting the expression of M4 receptors on D cells. No expression of M4 receptors was detected in the stomach of M4 KO mouse (a right figure of the lower panel), although the immunostaining of somatostatin was observed in this animal similar to WT mouse (data not shown).

\section{Changes in Serum Levels of Somatostatin after Administration of CCh in WT and M4 KO Mice}

Serum levels of somatostatin in WT mice under urethane anesthesia were $0.33 \pm 0.04 \mathrm{ng} / \mathrm{ml}$. The levels of somatostatin in M4 KO mice were slightly higher $(0.40 \pm 0.04 \mathrm{ng} / \mathrm{ml})$ than those in WT mice, although the difference was not statistically significant (Figure 7). On the other hand, the serum levels in WT mice were slightly but significantly decreased after the s.c. administration of CCh $(30 \mu \mathrm{g} / \mathrm{kg})$, the values being $0.22 \pm 0.01 \mathrm{ng} / \mathrm{ml}$. By contrast, the administration of CCh in M4 KO mice markedly increased the levels of somatostatin to $0.57 \pm 0.04 \mathrm{ng} / \mathrm{ml}$, the values being significantly higher than those in WT mice or those in M4 KO administered vehicle.

\section{Gene Expressions of mAChR Subtypes in Mouse Stomachs}

Since it was found that both M3 and M4 receptors were involved in the stimulatory action of $\mathrm{CCh}$ on gastric acid secretion, we examined the gene expressions of mAChR subtypes, M1-M5, in the mouse stomach. The expressions of M1-M5 mRNAs were all observed in the stomachs of WT mice, though the intensity slightly differed depending on the subtypes (Figure 8). The expressions of mAChRs were also observed in the stomachs of KO mice lacking M1-M5 receptors, except lacking a respective $\mathrm{mAChR}$ subtype in the corresponding KO mice. 


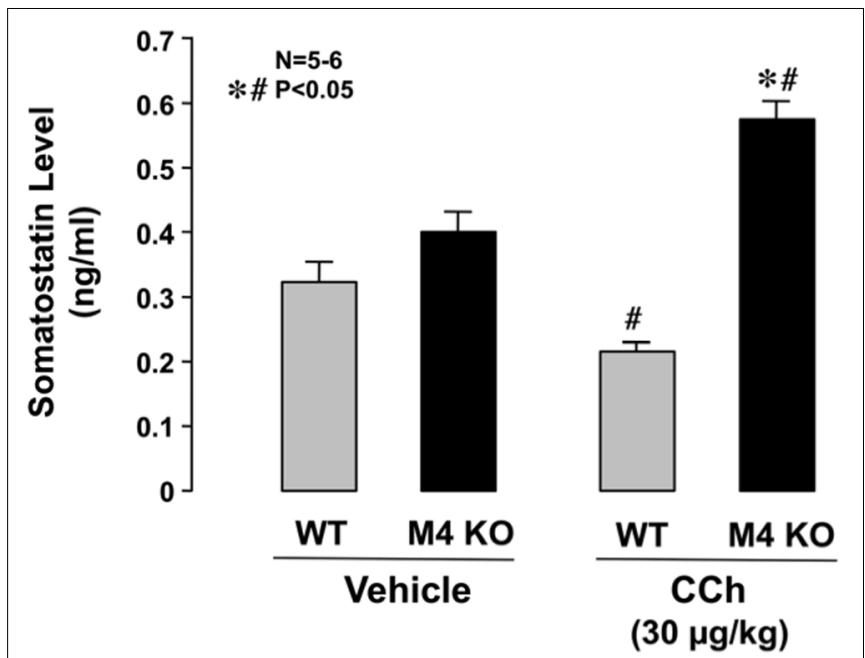

FIGURE 7 | Changes in serum somatostatin levels in WT or M4 KO mice after the administration of CCh. CCh $(30 \mu \mathrm{g} / \mathrm{kg})$ was administered S.c. as a single injection. Data are presented as the means \pm SE for 5 to 6 mice. Significant difference at $P<0.05$; * from WT; " from vehicle.

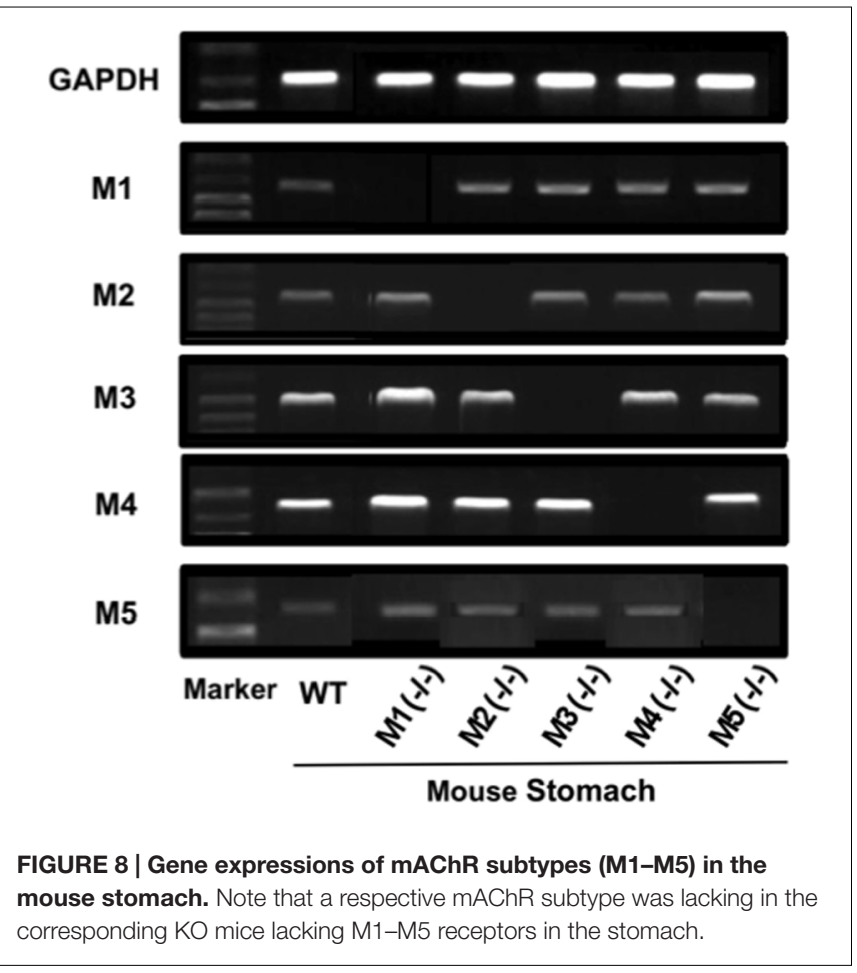

\section{DISCUSSION}

The parietal cell, which is responsible for gastric acid secretion, is known to express histamine $\mathrm{H} 2$ receptor and CCK2 receptors in addition to M3 receptors (Pfeiffer et al., 1990; Kajimura et al., 1992; Soll, 1994; Chen et al., 2004). The secretion of acid stimulated by Histamine or gastrin is mediated by the former two receptors, respectively (Brimblecombe et al., 1978;
Soll, 1994; Chen et al., 2004), while the subtypes of mAChRs responsible for cholinergic stimulation of acid secretion remains fully unexplored (Nakamura et al., 1985; Pfeiffer et al., 1990; Matsui et al., 2004; Aihara et al., 2005). The mechanism of cholinergic stimulation of acid secretion has been thought to involve M1 and M3 receptors (Nakamura et al., 1985; Pfeiffer et al., 1990), yet a recent study reported that gastric acid secretion was normally stimulated by histamine and gastrin as well as CCh in M1 KO mice, suggesting that M1 receptors are not involved in the regulation of gastric acid secretion in mice (Aihara et al., 2005). In the present study, we demonstrated for the first time the involvement of muscarinic M4 receptors in the regulatory mechanism of cholinergic stimulation of gastric acid secretion.

The mAChRs, consisting of five subtypes (M1-M5), are widely expressed in many peripheral organs to include the gastrointestinal tract (Kajimura et al., 1992; Helander et al., 1996; Matsui et al., 2000; Tobin et al., 2009). In the present study, we confirmed by RT-PCR analysis that all mAChR subtypes including M1-M5 were expressed in the mouse stomach, although the degree of expression differed depending on the subtype; M3 and M4 receptors were potently expressed while M1, M2, and M5 were expressed weakly. In addition, we also demonstrated that the expressions of mAChRs were also observed in the stomachs of $\mathrm{KO}$ mice lacking M1-M5 receptors, except lacking a respective $\mathrm{mAChR}$ subtype in the corresponding $\mathrm{KO}$ mice. Others reported the expression of M1 receptors on zymogen cells and surface mucosal cells (Xie et al., 2005), that of M3 receptors on parietal cells (Pfeiffer et al., 1990; Kajimura et al., 1992; Aihara et al., 2005), and those of M2 and M4 receptors on D cell (Sachs et al., 1997; Takeuchi et al., 2015).

We found that $\mathrm{CCh}$, a muscarinic agonist, dose-dependently increased acid secretion in the stomach of WT mice, and this response was almost completely inhibited by the prior administration of atropine, confirming the mediation of this secretion by the activation of $\mathrm{mAChR}$. Cholinergic stimulation of gastric acid secretion is thought to involve M1 receptors in addition to $\mathrm{M} 3$ receptors, because acid secretion was inhibited by pirenzepine, a selective M1 receptor antagonist (Nakamura et al., 1985). However, Aihara et al. (2005) examined the involvement of M1, M3, and M5 receptors in cholinergic regulation of acid secretion using muscarinic receptor $\mathrm{KO}$ mice and found that CCh-stimulated acid secretion is mediated by mainly M3 and partially M5 but not M1 receptors. They also demonstrated that pirenzepine exhibited similar inhibitory effects on CChstimulated acid secretion in both WT and M1 KO mice, suggesting that inhibition of acid secretion by pirenzepine is unlikely to result from M1-receptor blockade (2005). On the other hand, M5 receptors might be expressed in the enteric nervous system and mediates cholinergic stimulation of acid secretion by increasing Ach release from nerve endings and/or releasing histamine from enterochromaffin-like cells (Aihara et al., 2005).

In the present study, we found using $\mathrm{KO}$ mice lacking M1M5 receptors that CCh stimulated acid secretion in M1, M2, and M5 KO animals as effectively as in WT mice, but the stimulatory effect was markedly attenuated in M3, and M4 KO mice. We observed a slight decrease in the acid response to $\mathrm{CCh}$ 
in M5 KO mice, but the net acid output was not significantly different from that of WT mice. The reason for the different results between the study of Aihara et al. (2005) and our study, it may be due to different methods for acid measurement; they measure acid secretion in pylorus-ligated technique while we measured the secretion in the stomach with an acute fistula. Anyhow, it is therefore assumed that the cholinergic stimulation of gastric acid secretion is mediated by the activation of M3, and M4 receptors. In particular, the present study demonstrated for the first time the involvement of M4 receptors in the process of the CCh-stimulated gastric acid secretion, in addition to M3 receptors.

M3 receptors are coupled to $\mathrm{Gq} / 11$ protein to increase intracellular $\mathrm{Ca}^{2+}$ that mediates the secretion of acid as well as many hormones (Warhurst et al., 1996). Since acid secretion in response to $\mathrm{CCh}$ is known to be attenuated by a $\mathrm{Ca}^{2+}$ channel blocker, it is reasonable that M3 receptors are involved in the process of cholinergic stimulation of acid response (Pfeiffer et al., 1990; Aihara et al., 2005). It remains, however, unknown how the activation of M4 receptors modulates the acid response to $\mathrm{CCh}$ in the stomach. Since M4 receptors are coupled to Gi protein to decrease intracellular cAMP production (Caulfield and Birdsall, 1998), and since stimulation of gastric acid secretion is intracellularly mediated by cAMP, in addition to $\mathrm{Ca}^{2+}$ (Thurston et al., 1979; Soll, 1994; Hersey and Sachs, 1995), it is unlikely that M4 receptors are expressed in parietal cells and directly mediate the stimulation of acid secretion in response to CCh. Therefore, it is assumed that M4 receptors are expressed in cells other than parietal cells and indirectly affect the acid response to cholinergic stimulation.

By the way, somatostatin is synthesized in a variety of organs of the mammalian body and exerts almost ubiquitously an inhibitory action against various physiological processes (Lucey and Yamada, 1989). In the gastrointestinal tract, this peptide has been shown to inhibit motility and secretory functions and antagonizes the actions of several hormones (Lucey and Yamada, 1989; Warhurst et al., 1996; Terashima et al., 2009). Chiba and Yamada (1990) reported that CCh inhibited both basal and pentagastrin- stimulated somatostatin secretion in a Gi protein/cAMP-dependent manner in the isolated canine D cells. Five subtypes, SST1-SST5, of somatostatin receptors are currently known to exist, and all of them are expressed in the gastrointestinal tract (Chiba and Yamada, 1990; Krempels et al., 1997; Patel, 1997). It is thus possible that the activation of M4 receptors inhibits somatostatin secretion from $\mathrm{D}$ cells and by so doing indirectly affect acid secretion. If this is the case, the followings should be demonstrated; (i) somatostatin suppresses the acid response to cholinergic stimulation such as CCh, (ii) the decreased acid response in M4 KO mice can be reversed by the SST2 antagonist, and (iii) the release of somatostatin from $\mathrm{D}$ cells is increased in M4 KO mice. As expected, we found that CCh-stimulated acid secretion was significantly suppressed by octreotide, the somatostatin analog. We also found that the suppressed acid response to $\mathrm{CCh}$ in $\mathrm{M} 4 \mathrm{KO}$ mice was significantly restored by the prior application of the somatostatin SST2 antagonist, CYN154806. In addition, it was found that serum somatostatin levels were significantly increased in M4 KO

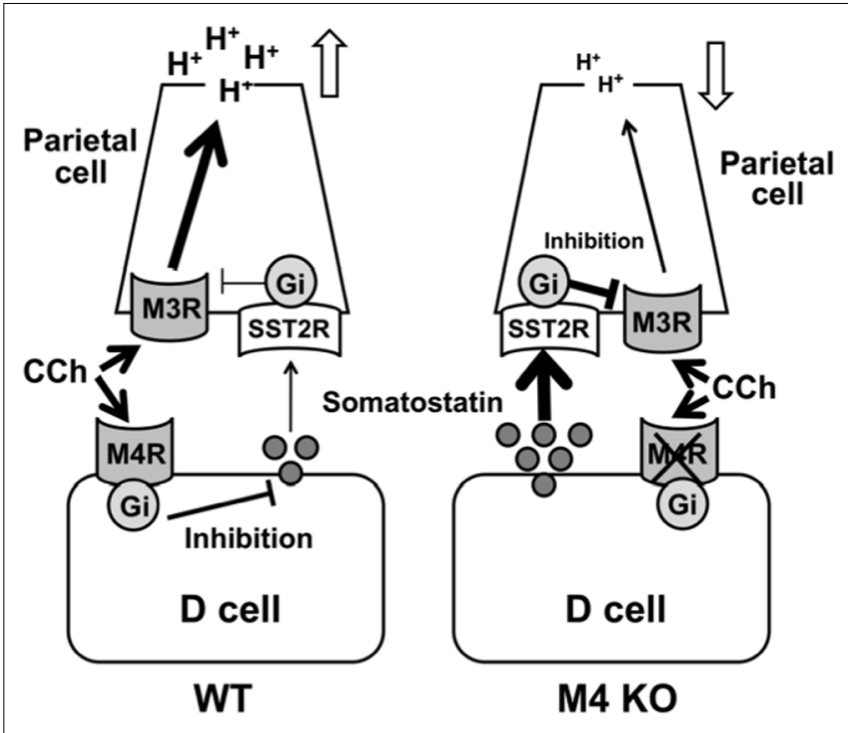

FIGURE 9 | Working hypothesis for the involvement of M4 receptors in the regulatory mechanism of cholinergic stimulation of gastric acid secretion. The cholinergic stimulation of acid secretion is mediated by the activation of M3 and M4 receptors. The activation of M3 receptors directly affects acid secretion from the parietal cells through a Gq protein/ $\mathrm{Ca}^{2+}$ pathway, while the activation of M4 receptors inhibits somatostatin secretion from $D$ cells and by so doing unmasks the stimulatory effect of CCh mediated by the activation of $\mathrm{M} 3$ receptors in the parietal cells.

mice under CCh-stimulated conditions. These results strongly support our hypothesis that the decrease of CCh-induced acid response in M4 $\mathrm{KO}$ mice is explained by the inhibitory effect of somatostatin mediated by SST2 receptors. It is therefore assumed that the activation of M4 receptors inhibits somatostatin release from $\mathrm{D}$ cells and negates the negative influence of this peptide on acid secretion, resulting in a potentiation of the acid response to CCh. Certainly, more studies are needed to clarify the regulatory mechanisms of somatostatin secretion from $D$ cells.

Finally, it remains undefined whether M4 receptors are really expressed on D cells? We performed the immunostaining of the gastric mucosa with anti-somatostatin and anti-M4 receptor antibodies in WT mice. The histological observation showed that M4 receptors were co-expressed with somatostatin, indicating the expression of M4 receptors on D cells. We confirmed that M4 receptors were not observed in the stomachs of $\mathrm{M} 4 \mathrm{KO}$ mice. These results strongly suggest that $\mathrm{CCh}$ inhibits somatostatin release from D cells via the activation of M4 receptors. The present study was performed in mice anesthetized with urethane. Since this anesthetic is known to promote the secretion of somatostatin from D cells (Saito et al., 1979), the results obtained in this study might differ from those obtained under normal physiological conditions. However, since CYN154806 by itself had no effect on basal acid secretion, it is assumed that the interpretation of the present results is not affected by urethane anesthesia.

Given the findings of the present study, we conclude that the cholinergic stimulation of gastric acid secretion is mediated by 
the activation of $\mathrm{M} 3$ receptors in parietal cells and modified indirectly by M4 receptors in D cells (Figure 9). It is assumed that the activation of $\mathrm{M} 4$ receptors inhibits the release of somatostatin from $\mathrm{D}$ cells to result in enhancement of the acid response by removing the negative influence of somatostatin via the activation of SST2 receptors.

\section{AUTHOR CONTRIBUTIONS}

KT authored the paper and designed the study; TE, $\mathrm{SH}$, and TA performed the experiments; $\mathrm{TE}$ and $\mathrm{SH}$ performed data

\section{REFERENCES}

Aihara, T., Nakamura, Y., Taketo, M. M., Natsui, M., and Okabe, S. (2005). Cholinergically stimulated gastric acid secretion is mediated by M3 and M5 but not M1 muscarinic acetylcholine receptors in mice. Am. J. Physiol. 288, G1199-G1207.

Amagase, K., Ochi, A., Sugihara, T., Kato, S., and Takeuchi, K. (2010). Protective effect of lafutidine, a histamine $\mathrm{H} 2$ receptor antagonist, against loxoprofeninduced small intestinal lesions in rats. J. Gastroenterol. Hepatol. 25, S111-S118. doi: 10.1111/j.1440-1746.2010.06223.x

Brimblecombe, R. W., Duncan, W. A. M., Durant, G. J., Emmett, J. C., Ganelin, C. R., and Parsons, M. E. (1978). Characterization and development of cimetidine as a histamine H2-receptor antagonist. Gastroenterology 74, 339347.

Caulfield, M. P., and Birdsall, N. J. M. (1998). International union of pharmacology. XVII. Classification of muscarinic acetylcholine receptors. Pharmacol. Rev. 50, 279-290.

Chen, D., Zhao, C. M., Hakanson, R., Samuelson, L. C., Rehfeld, J. F., and Friis-Hansen, L. (2004). Altered control of gastric acid secretion in gastrin/cholecyctokinin double mutant mice. Gastroenterology 126, 476-487. doi: 10.1053/j.gastro.2003.11.012

Chiba, T., and Yamada, T. (1990). Mechanisms for muscarinic inhibition of somatostatin release from canine fundic D cells. Metabolism 39, 122-124. doi: 10.1016/0026-0495(90)90228-5

Feniuk, W., Jarvie, E., Luo, J., and Humphrey, P. P. (2000). Selective somatostatin sst (2) receptor blockade with the novel cyclic octapeptide, CYN-154806. Neuropharmacology 39, 1443-1450. doi: 10.1016/S0028-3908(00)00035-6

Hayashi, S., Kurata, N., Yamaguchi, A., Amagase, K., and Takeuchi, K. (2014). Lubiprostone prevents NSAID-induced small intestinal damage by suppressing the expression of inflammatory mediators via EP4 receptors. J. Pharmacol. Exp. Ther. 349, 470-479. doi: 10.1124/jpet.114.213991

Helander, K. G., Bamberg, K., Sachs, G., Melle, D., and Helander, H. F. (1996). Localization of mRNA for the muscarinic receptor in rat stomach. Biochem. Biophys. Acta. 1312, 158-162. doi: 10.1016/0167-4889(96)00021-3

Hersey, S. J., and Sachs, G. (1995). Gastric acid secretion. Physiol. Rev. 75, 155-189.

Kajimura, M., Reuben, M. A., and Sachs, G. (1992). The muscarinic receptor gene expressed in rabbit parietal cells is the m3 subtype. Gastroenterology 103, 870-875. doi: 10.1016/0016-5085(92)90019-U

Kitamura, M., Sugamoto, S., Kawauchi, S., Kato, S., and Takeuchi, K. (1999). Modulation by endogenous nitric oxide of acid secretion induced by gastric distension in rats: enhancement by nitric oxide synthase inhibitor. J. Pharmacol. Exp. Ther. 291, 181-187.

Krempels, K., Hunyady, B., O'Carroll, A. M., and Mezey, E. (1997). Distribution of somatostatin receptor messenger RNAs in the rat gastrointestinal tract. Gastroenterology 112, 1948-1960.

Lucey, M. R., and Yamada, T. (1989). Biochemistry and physiology of gastrointestinal somatostatin. Dig. Dis. Sci. 34, 5S-13S. doi: 10.1007/ BF01536041

Matsui, M., Motomura, D., Karasawa, H., Fujikawa, T., Jiang, J., Komiya, Y., et al. (2000). Multiple functional defects in peripheral autonomic organs in mice lacking muscarinic acetylcholine receptor gene for the M3 subtype. Proc. Natl. Acad. Sci. U.S.A. 97, 9579-9584. doi: 10.1073/pnas.97.17.9579 analysis and coauthored the paper; KT contributed to critical revision of the paper. All authors approved the submission of the manuscript.

\section{ACKNOWLEDGMENT}

The authors are greatly indebted to the undergraduate students at Department of Pharmacology and Experimental Therapeutics, Kyoto Pharmaceutical University, Kyoto, Japan, for their technical collaboration.

Matsui, M., Yamada, S., Oki, T., Manabe, T., Taketo, M. M., and Ehlert, F. J. (2004). Functonal analysis of muscarinic acetylcholine receptors using knockout mice. Life. Sci. 75, 2971-2981. doi: 10.1016/j.lfs.2004.05.034

Nakamori, Y., Komatsu, Y., Kotani, T., Kojima, S., and Takeuchi, K. (2010). Pathogenic importance of cysteinyl leukotrienes in development of gastric lesions induced by ischemia/reperfusion in mice. J. Pharmacol. Exp. Ther. 333, 91-98. doi: 10.1124/jpet.109.162578

Nakamura, M., Oda, M., Yonei, Y., Tsukada, N., Komatsu, H., Kaneko, K., et al. (1985). Muscarinic acetylcholine receptors in rat gastric mucosa. Histochemistry $83,479-487$.

Nakamura, T., Matsui, M., Uchida, K., Futatsugi, A., Kusakawa, S., Matsumoto, N., et al. (2004). M3 muscarinic acetylcholine receptor plays a critical role in parasympathetic control of salivation in mice. J. Physiol. 558, 561-575. doi: 10.1113/jphysiol.2004.064626

Niida, H., Takeuchi, K., and Okabe, S. (1991). Role of thyrotropin-releasing hormone in acid secretory response induced by lowering of body temperature in the rat. Eur. J. Pharmacol. 198, 137-142. doi: 10.1016/0014-2999(91)90612-T

Ohno-Shosaku, T., Matsui, M., Fukudome, Y., Shosaku, J., Tsubokawa, H., Taketo, M. M., et al. (2003). Postsynaptic M1 and M3 receptors are responsible for the muscarinic enhancement of retrograde endocannabinoid signalling in the hippocampus. Eur. J. Neurosci. 18, 109-116. doi: 10.1046/j.14609568.2003.02732.x

Patel, Y. C. (1997). Molecular pharmacology of somatostatin receptor subtypes. J. Endocrinol. Invest. 20, 348-367. doi: 10.1007/BF03350317

Pfeiffer, A., Rochlitz, H., Noelke, B., Tacke, R., Moser, U., Mutschler, E., et al. (1990). Muscarinic receptors mediating acid secretion in isolated rat gastric parietal cells are of M3 type. Gastroenterology 98, 218-222. doi: 10.1016/00165085(90)91314-V

Piqueras, L., and Martínez, V. (2004). Role of somatostatin receptors on gastric acid secretion in wild-type and somatostatin receptor type 2 knockout mice. Naunyn Schmiedebergs Arch. Pharmacol. 370, 510-520. doi: 10.1007/s00210-004-0992-8

Sachs, G., Zeng, N., and Prinz, C. (1997). Physiology of isolated gastric endocrine cells. Annu. Rev. Physiol. 59, 243-256. doi: 10.1146/annurev.physiol. 59.1.243

Saito, H., Ogawa, T., Ishimaru, K., Oshima, I., and Saito, S. (1979). Effect of pentobarbital and urethane on the release of hypothalamic somatostatin and pituitary growth hormone. Horm. Metab. Res. 10, 550-554. doi: 10.1055/s-00281092778

Soll, A. H. (1994). "Receptors that regulate acid secretory function," in Physiology of the Gastrointestinal Tract, ed. L. R. Johnson (New York, NY: Raven Press), 1139-1170.

Takeuchi, K., Kita, K., Takahashi, K., Aihara, E., and Hayashi, S. (2015). Muscarinic acetylcholine receptor subtype 4 is essential for cholinergic stimulation of duodenal HCO3- secretion in mice: relationship to $\mathrm{D}$ cell/somatostatin. J. Physiol. Pharmacol. 66, 391-401.

Terashima, S., Nishio, H., Ogura, M., Honda, M., and Takeuchi, K. (2009). Involvement of prostacyclin/IP receptors in decreased acid response of damaged stomachs -Mediation by somatostatin/SST2 receptors. Life. Sci. 84, 172-180. doi: 10.1016/j.lfs.2008.11.014

Thurston, D., Tao, P., and Wilson, D. E. (1979). Cyclic nucleotides and the regulation of canine gastric acid secretion. Dig. Dis. Sci. 24, 257-264. doi: 10.1007/BF01296537 
Tobin, G., Giglio, D., and Lundgren, O. (2009). Muscarinic receptor subtypes in the alimentary tract. J. Physiol. Pharmacol. 60, 3-21.

Warhurst, G., Higgs, N. B., Fakhoury, H., Warhurst, A. C., Garde, J., and Coy, D. H. (1996). Somatostatin receptor subtype 2 mediates somatostatin inhibition of ion secretion in rat distal colon. Gastroenterology 111, 325-333. doi: 10.1053/gast.1996.v111.pm8690197

Xie, G., Drachenberg, C., Yamada, M., Wess, J., and Raufman, J. P. (2005). Cholinergic agonist-induced pepsinogen secretion from murine gastric chief cells is mediated by M1 and M3 muscarinic receptors. Am. J. Physiol. 289, G521-G529.
Conflict of Interest Statement: The authors declare that the research was conducted in the absence of any commercial or financial relationships that could be construed as a potential conflict of interest.

Copyright (c) 2016 Takeuchi, Endoh, Hayashi and Aihara. This is an open-access article distributed under the terms of the Creative Commons Attribution License (CC BY). The use, distribution or reproduction in other forums is permitted, provided the original author(s) or licensor are credited and that the original publication in this journal is cited, in accordance with accepted academic practice. No use, distribution or reproduction is permitted which does not comply with these terms. 